\title{
Industrial Drying TechniQues in Agriculture of Turkey
}

\section{Short Communication}

Volume 2 Issue 1- 2021

\author{
Author Details \\ Hasan ÖZÇELİK* \\ Department of Biology, Süleyman Demirel University, Turkey \\ *Corresponding author \\ Hasan ÖZÇELIKK. Department of Biology, Süleyman Demirel University, Science Faculty, 12345, Isparta, Turkey \\ Article History \\ Received: January 05, 2021 Accepted: January 12, 2021 Published: January 13, 2021
}

\begin{abstract}
This article is a compilation of small volume, describes the industrial drying of agricultural products in Turkey. Although our trial in Turkey has focused on various drying techniques, vacuum drying and drying in tray. The technical features of the vacuum drying system are described in the article. Drying technology is a rapidly rising value in recent times. It is a hope for humanity who is likely to suffer from food shortages in 2021 year.
\end{abstract}

Keywords: Industrial drying, Technology, Agriculture, Vegetables, Fruits, Spices

\section{Introduction}

Turkey is a very rich country in terms of natural and cultural diversity of plants $[1,2]$. Despite its small area, it has rich flora like a continent. It is among the self-sufficient agricultural countries. There are dozens, hundreds of varieties from each fruit variety in the country. On the other hand, the plant use culture in it is particularly rich in cuisine. Culinary culture and some special foods of various provinces have been registered as Unesco World Heritage. Turkey's provisional list of 73 cultural and 2 mixed heritage and has a total of 77, including 2 natural. Bread types, Turkish Coffee, Kesgek (local special) are among them. In the UNESCO Creative Cities Network, gastronomy, design and craft from various regions have been taken into consideration. The Hitit and Kültepe tablets (in drugs) were also recorded in the same way. There are more important local values to be recorded. Historical facts reveal that it is a very important country in medicine and gastronomy [3]. Göbeklitepe (Şanlıurfa) is in itself a treasure of cultural and natural qualities.

\section{Problem Description}

Turkey, the need for more agricultural products (vegetables, fruits and spices) is producing. A part of this is being used because it cannot be consumed or sold. In Turkey, dried fruit, vegetables and aromatic plants the production is still carried out with conventional methods in general. In practice, drying in industrial ovens is not common.
In addition, aromatic plants dried in industrial ovens have a weaker customer preference. The results of physical, chemical, biological and sensory analyzes such as color, flavor, aroma are not as successful as traditional methods. Many manufacturers carry out this drying process in uncontrolled, outdoor conditions. Drying without pre-drying and final drying controls (humidity, temperature, final humidity, air flow etc.) before starting the drying process leads to failure to obtain the desired quality product. For this reason, industrial drying of agricultural products has gained speed recently, and manufacturers have turned to drying techniques.

\section{Purpose of drying the product}

Drying is a known and applied method in many fields. The subject that is tried to be explained here is the industrial drying of agricultural products. Drying is generally defined as the process of removing water from food, spice or targeted product/raw material. With drying, the moisture content in the product decreases. Consequently, their volumes decrease and the dry matter ratio increase. Packaging, storage and transportation costs are reduced, and operations are simplified. It may be possible to consume the products not only seasonally but throughout year. It enables the design of new food products. Especially instant soups, herbal teas and coffees etc. The systems used in the drying process: They are widely used in many branches of the agricultural industry (food, spices, vegetables, fruits, etc.) [4]. 


\section{Industrial vacuum dryers and their advantages}

To reduce the atmospheric pressure with a vacuum pump in a robust cabinet and to dry the interior with a heater, fan and rotary table systems. Low atmospheric pressure allows the pressure drying temperature to be achieved at lower levels. It can be used in pharmaceutical industry, chemical industry, fruit and vegetable drying fields. Drying is generally done at 45-55 degrees in it. The machine has temperature sensor, humidity sensor, pressure sensor, refrigerated input and output temperature control, weighing systems and touch screen PLC control unit. It has low energy cost, the ability to dry sensitive products at lower temperatures while drying, and the ability to take additional liquid during drying and drying without oxygen or with different gases. Low atmospheric pressure facilitates drying with the boiling point of water. It is especially preferred for drying sensitive products.

\section{Preparation for product processing}

Oily and waxy products are not preferred for drying. It is very difficult to dry. In addition, not all agricultural products can be dried. For example, there are many varieties of apples Not all varieties are suitable for drying. In the drying process, the oven temperature is around $40^{\circ} \mathrm{C}$. At this temperature, the apple darkens. Bananas are like that. Drying requires a special skill. The agricultural products to be dried are first washed and then air dried. It is cut / chopped in different shapes and sizes on machines. Accordingly, the processed products are named; powder, granule etc. Then they are put into drying ovens. They are packaged and stored or sold after drying. Some products undergo a second treatment after drying. This process is to powder the product. Mushrooms, rose flowers, garlic, onions are such products. Companies that convert raw materials into products prefer to use it in powder form more.

\section{Trial Results}

Our trials cover the last 6 years and are mostly aimed at fruits, vegetables and spices. In Turkey, dried fruit especially has made a significant contribution to foreign trade income. The water ratio in the final product should be about $4 \%$. The final product is at most $1 / 10$ of the raw material. It may decrease to $1 / 30$ in those with very high-water rate. For export, there should be no deterioration such as darkening or mold on the product. Preservative food additives and flavorings in the proceeding should not be used. Amount of the final product matters determine the cost calculation. The cost varies a lot depending on the product. In addition to products such as melon, watermelon, mushrooms, which have 95\% water; potatoes, dried beans and garlic which have less water do not give the same result. It means that higher water rate, the higher cost.
The added value of dried products varies according to the product but increases at least 4 times according to raw materials. It provides a standardization in uniform product marketing. Drying provides many advantages in product sales, storage, transportation and use. The most important thing is that the surplus products are evaluated, the farmers are guaranteed to be purchased and the continuity of production is ensured. The companies that use these products become permanent customers, increasing their consumption volume gradually. Meanwhile, new products are developed. With the development of the drying industry, the diversification and product volume increased in ready-made foods. For example, instant soup, meal etc. Foods that are short-term and easy to prepare and at the same time cheaper can be produced. Drying products were preferred in cake, instant soup, instant tea / coffee and confectionery.

According to our observations, the countries where dried herbal products are sold most to America, England, China, Bulgaria, Kyrgyzstan, Iraq, Azerbaijan, Qatar, Bosnia and Herzegovina, etc. Before from Turkey, Europe and the US met with drying implements industry. However, they generally add food additives to products and dry them. Naturalness and simplicity are features sought in our time. Both doped in Turkey as well as unadulterated food products are produced. Although the value of additive-free ones is very high, they are preferred in exports. There is little demand for additive and protective products. An advantage of industrial drying is that separate machines are designed for some products. This improves the agricultural industry. A separate planning should be made for each of the products without additives. For this reason, the working program of the machine should be planned separately. Drying time is longer for the proceeding. This means an increase in costs.

a) In Turkey, the most industrially dried vegetables: mushrooms, tomatoes, potatoes, garlic, beans, leeks, carrots, broccoli, spinach, peppers, okra, peas, lentils.

b) Fruits: Apple, banana, strawberry, pomegranate, pear, apricot, berry, lemon, orange, grapefruit, pear, plum, sour grape, cherry, sour cherry, melon, watermelon, mango, pineapple.

c) Spices: Pepper, thyme, mint.

d) Medicinal plants: Rose, rosehip, lavender, sahlep.

e) Ready meals: Cake, soup, rice, beans and mixed foods etc.

The results of drying with the same method in their genotypes were very different. Below are examples of our drying machines and works. We hope that our trial results will give a contribution to humanity and a horizon for scientists.

Table 1: Different oil roses (Rosa damascena) below has been prepared as an example[5].

\begin{tabular}{|c|c|c|c|c|}
\hline $\begin{array}{c}\text { Sample Number } \\
\text { (Özçelik) }\end{array}$ & Dry Rose Amount (g) & Solid Matter (\%) & Liquid Extract Amount (g) & Solid Extract Amount (g) \\
\hline 626 & 160 & 15,2 & 120 & 18,24 \\
\hline 2224 & 360 & 15,2 & 290 & 34,08 \\
\hline 2389 & 340 & 14,2 & 265 & 30,60 \\
\hline 1614 & 280 & 17 & 180 & 13,4 \\
\hline $513-b$ & 180 & 13,4 & 100 & 11,92 \\
\hline 1561 & 100 & 29,8 & 40 & \\
\hline
\end{tabular}


Table 2: The amount of some fruit products we obtained in drying works [5].

\begin{tabular}{|c|c|c|}
\hline Fruits & Latinish Name of Plant & Drying Product Amount \\
\hline Orange & Citrus sinensis & $16-17 \%$ \\
\hline Banana & Musa cavendishii & $23-25 \%$ \\
\hline Strawberry & Fragaria vesca & $8-9 \%$ \\
\hline Apple & Malus domestica & $13-14 \%$ \\
\hline Pomegranate & Punica granatum & $23-25 \%$ \\
\hline Melon & Cucumis melo & $8-9 \%$ \\
\hline Watermelon & Citrullus lanatus & $7.5-9 \%$ \\
\hline Peach & Prunus persica & $10.5-11.5 \%$ \\
\hline
\end{tabular}

Table 3: Drying parameters of some dried products [5].

\begin{tabular}{|c|c|c|c|}
\hline Products and Drying Conditions & Melon & Mushrooms & Lavander \\
\hline Drying temperature & $80^{\circ} \mathrm{C}$ & $60^{\circ} \mathrm{C}$ & $45^{\circ} \mathrm{C}$ \\
\hline Drying moisture & $\% 6$ & $\% 7$ & $\% 10$ \\
\hline Drying time & $390 \mathrm{dk}$ & $320 \mathrm{dk}$ & $210 \mathrm{dk}$ \\
\hline Initial moisture (Raw product moisture) & $\% 91$ & $\% 89$ & $\% 90$ \\
\hline Final moisture (Dry product moisture) & $\% 10$ & $\% 9$ & $\% 10$ \\
\hline Tray rotation speed & 7 cycle repeats/dk & 5 cycle repeats/dk & 5 cycle repeats/dk \\
\hline Air flow rate & $2 \mathrm{~m}^{3} / \mathrm{sn}$ & $1.3 \mathrm{~m}^{3} / \mathrm{sn}$ & $4 \mathrm{~m}^{3} / \mathrm{sn}$ \\
\hline Product shape & Chopped into thin slices & Slide chopped slices & Freshly harvested with stem \\
\hline The product that can be dried in $1 \mathrm{~m}^{2}$ area & $8 \mathrm{~kg}$ & $4 \mathrm{~kg}$ & $2 \mathrm{~kg}$ \\
\hline
\end{tabular}
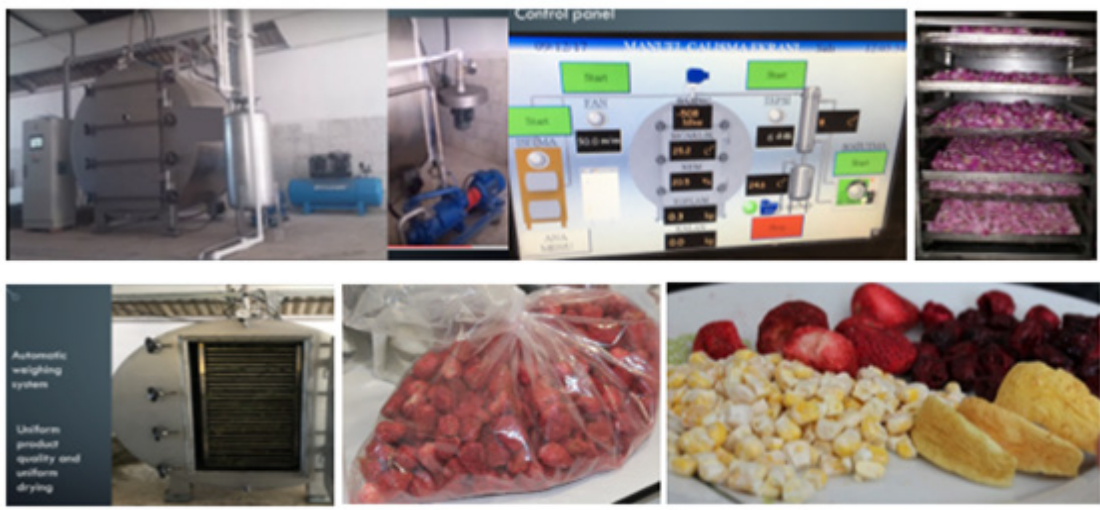

Figure 1: Industrial drying systems and products [5].

\section{References}

1. Davis PH (1965-1985) Flora of Turkey and the Aegean Islands. 1-9, Edinburgh Univ. Press.

2. Öztürk M, Özçelik H (1991) Doğu Anadolu’nun Faydalı Bitkileri (Useful Plants of East Anatolia), SİSKAV Vakfı (Siirt), Semih Ofset ve Matb, Ankara.

3. https://www.dogrulukpayi.com/bulten/unesco-miras-listesi-nde-turkiyeden-nereler-var?gclid=CjwKCAiArbv_BRA8EiwAYGs23NOci7xOF0FBn 6zRETE15LoM-KnE_wcTtHsIcWdnbl9dft8cSyvXuBoCTp4QAvD_BwE).
4. Özçelik H (2018) Local Products From Türkiye Roses (Rosa L. Spp.) And Therr Importances For Health, 1st International Health Sciences and Life Congress, 02-05 May 2018, Burdur/Turkey, Full Text Book, pp. 1236-1247.

5. Özçelik H., Özçelik MM, Poyraz M (2018) New Technological Approaches to Drying Aromatic Plants in Industrial Furnaces, 1st International Health Sciences and Life Congress, 02-05 May 2018, Burdur/Turkey, Full Text Book, pp. 1259-1272. 